\title{
Biological and photochemical processes underlying latitudinal changes in molecular composition of dissolved organic matter in the surface Pacific Ocean
}

\author{
Penghui Li ${ }^{1}$, Chen He ${ }^{2}$, QuAn ShI ${ }^{2}$, ChuANLun \\ ZHANG $^{1}$
}

${ }^{1}$ Shenzhen Key Laboratory of Marine Archaea Geo-Omics, Department of Ocean Science and Engineering, Southern University of Science and Technology, Shenzhen 518055, China. Lipenghui1987@126.com ,

zhangcl@sustech.edu.cn

${ }^{2}$ State Key Laboratory of Heavy Oil Processing, China

University of Petroleum, Beijing 102249, China.

hechen1028@126.com, sq@.cup.edu.cn

Marine dissolved organic matter (DOM) is one of the largest organic carbon pools on the earth and plays an important role in global carbon cycling. The reactivity of DOM significantly depends on its molecular composition, which is manifested in its spatial and temporal distributions mediated by abiotic and biotic processes in the ocean. In this study, water samples were collected from the surface Pacific Ocean from $0^{\circ} \mathrm{N}$ to $22^{\circ} \mathrm{N}$ and characterized using absorbance and fluorescence spectroscopy and high-resolution mass spectrometry. Three fluorescent components (protein-like $\mathrm{C} 1$ and $\mathrm{C} 3$, and humic-like $\mathrm{C} 2$ ) were identified by parallel factor analysis (PARAFAC) of fluorescence data. The aromaticity index (AImod) and relative abundance (RAMLBL) of labile formulas $(\mathrm{H} / \mathrm{C}>1.5)$ were derived from high-resolution mass spectrometry. Protein-like C3 showed much higher percentage in low-latitudes $\left(0^{\circ} \mathrm{N}-12^{\circ} \mathrm{N}\right)$ than that in higherlatitudes $\left(12^{\circ} \mathrm{N}-22^{\circ} \mathrm{N}\right)$, which could be possibly linked with high primary production in low-latitudes. In addition, absorbance spectra of DOM showed shoulder peaks around $280 \mathrm{~nm}$ in low latitude- but not high latitude samples, indicating the contribution of chromophores resulting from primary production. Moreover, AImod decreased and RAMLBL increased from the high latitude to the low high latitude, which could possibly be attributed to high solar radiation and thus photodegradation of aromatic formulas and production of labile formulas through primary production in low-latitudes. Together, our results showed that the latitudinal changes in molecular composition of DOM may reflect a combination of changing primary production and solar radiation along latitude, which should be taken into consideration when evaluating the sources and fates of DOM in global oceans. 